\title{
Suction Retrieval of Esophageal Foreign Bodies
}

The majority of foreign bodies are found in the esophagus $(1,2)$, and can be removed using a flexible endoscope $(2,3)$. Firm oval foreign bodies in the esophagus cause severe dysphagia due to a ball-valve mechanism. The seed of the jambo or jambul fruit (Eugenia jambos, Jambosa vulgaris, or "rose apple") is oval, with a maximum diameter of $1.8-2.2 \mathrm{~cm}$. We report here a new method of removing jambo fruit seeds.

Eight patients with corrosive strictures (six children aged three to five, and two adults aged 28 and 35 ) presented with a sudden worsening of dysphagia after ingesting jambo fruits. At endoscopy, the jambo seed was visualized proximal to the corrosive strictures, and was mobile in all the patients. It was not possible to push the seeds distal to the stricture by exerting force from the endoscope tip.

The housing cylinder of an endoscopic variceal ligator (Sunray endoscopic variceal ligator, Suntech Research Center, Jaipur, India) was tightly fitted over the tip of the endoscope (an Olympus XQ-10 gastroscope). The endoscope was introduced into the esophagus, and the tip of the instrument was kept in close approximation to the foreign body, with continuous suction being applied as the endoscope was then removed again (Figure 1). The mean time required to remove the seed was $1 \mathrm{~min} 45 \mathrm{~s}$ to $2 \mathrm{~min}$.

Applying the outer cylinder of a variceal ligator instrument when removing this type of foreign body works on the principle of creating a vacuum between tip of the endoscope and the smooth, firm and oval foreign body in close proximity to the tip of the housing cylinder. The seeds remained attached to the tip of the instrument due to the continuous suction, which was maintained until the seed was removed. This method seems to be a very effective, safe, and quick way of removing of firm oval foreign bodies.

\section{S. Nijhawan, R.R. Rai, S. Nepalia,}

\section{R. Pokharna}

Dept. of Gastroenterology,

S.M.S. Medical College, Jaipur, India

\section{References}

1. Webb WA. Management of foreign bodies of the upper gastrointestinal tract: update. Gastrointest Endosc 1995; 41: 39-51

2. Mangal BD, Mangal Y, Pandey RP Retrieval of foreign body from upper GI tract by flexible fibreoptic endoscope: an experience. J Assoc Physicians India 1993; 41: 11-3.

3. Bendig DW. Removal of blunt esophageal foreign bodies by flexible endoscopy without general anesthesia. Am J Dis Child 1986; 140: 789-90.

Corresponding Author

S. Nijhawan, M.D.

Associate Professor

of Gastroenterology

S.M.S. Medical College

Jaipur, India

Fax: +91-141-520163

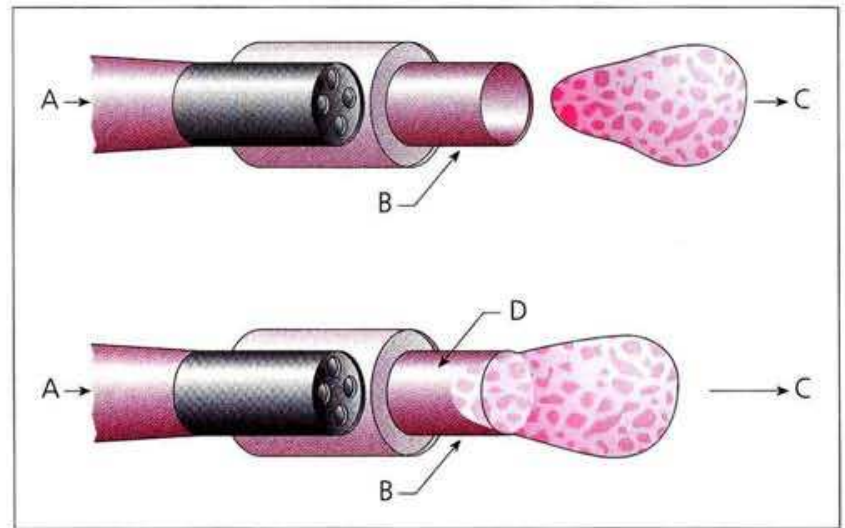

Figure 1: Suction retrieval of a foreign body in the esophagus. A: Tip of the endoscope; B: housing cylinder of the ligator instrument; $\mathrm{C}$ : foreign body; D: vacuum. 